\title{
Complementary Therapies in Allergic Rhinitis
}

\author{
Ibrahim Sayin, ${ }^{1}$ Cemal Cingi, ${ }^{2}$ Fatih Oghan, ${ }^{3}$ Bahadir Baykal, ${ }^{1}$ and Seckin Ulusoy ${ }^{4}$ \\ ${ }^{1}$ Otorhinolaryngology-Head and Neck Surgery Department, Bakırkoy Dr. Sadi Konuk Training and Research Hospital, \\ 34147 Istanbul, Turkey \\ ${ }^{2}$ Department of Otorhinolaryngology, Faculty of Medicine, Osmangazi University, 26480 Eskisehir, Turkey \\ ${ }^{3}$ Department of ORL\&HNS, Medical School, Dumlupinar University, Central Campus, Tavsanli Yolu 10 km, 43270 Kutahya, Turkey \\ ${ }^{4}$ Corlu State Hospital, Department of Otorhinolaryngology, 59850 Tekirdag, Turkey
}

Correspondence should be addressed to Fatih Oghan; fatihoghan@hotmail.com

Received 8 July 2013; Accepted 19 September 2013

Academic Editors: M. Iikura, P. Piirilä, and T. A. Popov

Copyright (C) 2013 Ibrahim Sayin et al. This is an open access article distributed under the Creative Commons Attribution License, which permits unrestricted use, distribution, and reproduction in any medium, provided the original work is properly cited.

Objective. To determine the prevalence of herbal treatment of allergic rhinitis. Methods. In this prospective study, patients who were diagnosed with perennial allergic rhinitis were questioned about their use of natural products/herbal therapies for their symptoms. Results. In total, 230 patients were enrolled. Overall, $37.3 \%$ of the patients stated that they had used natural products/herbal therapies at least once. Women were more likely than men to use herbal supplements (38.3\% versus 32.4\%). Ten different types of herbal supplements were identified, with stinging nettle (Urtica dioicath), black elderberry (Sambucus nigra), and Spirulina being the most common $(12.6 \%, 6.1 \%$, and $5.7 \%$, resp.). Conclusion. This study found a high prevalence of herbal treatment usage for the relief of allergic rhinitis symptoms in Turkey. The herbal products identified in this study and in the literature are discussed.

\section{Introduction}

Along with acupuncture, yoga, massage, and speleotherapy, herbal therapy (HT) is a therapeutic option available as complementary alternative medicine (CAM) [1]. It has a long historical tradition, with the medicinal use of herbs being reported as early as 2800 BC. Around 400 BC, Hippocrates described the relationship between nutrition and health as "Food be medicine and medicine be food" [2].

In recent years, traditional therapies have gained in popularity for medical and economic reasons, in both developing and industrialized countries [3]. The prevalence of herbal therapy use differs according to country and medical condition. The general literature indicates that $25-50 \%$ of the general population and up to $70 \%$ of children have used a CAM method at least once [1]. A study in Americans demonstrated a $29 \%$ prevalence of HT use for rhinosinusitis [4]. In a study from Spain, $34.4 \%$ of 400 patients with allergic diseases (allergic rhinitis, asthma, and atopic dermatitis) had used at least one type of alternative medicine, and among these patients, $31.5 \%$ had used a natural medicine [5]. A recent study from
England demonstrated that $65 \%$ of those questioned had used CAM for rhinosinusitis or nasal polyposis [6]. A study from Israel reported a rate of $19 \%$ for the use of CAM to treat rhinosinusitis [7].

Herbal therapies have a variety of pharmacological actions, as well as potential adverse effects and potential drug interactions. Some HTs produce bleeding, cardiovascular instability, or altered glucose levels. Others can potentiate the sedative effects of anesthesia and increase the metabolism of drugs during the postoperative period. Thus, the American Association of Anesthesia recommends that HTs be stopped 2-3 weeks before surgery [8].

Given the widespread and growing use of HTs and their potential pharmacodynamic and pharmacokinetic effects, an understanding of the use of HTs for various conditions would be beneficial for physicians. This idea is supported by several studies, including one that reported the need among general practitioners and allergy/immunology specialists for more knowledge about complementary medicine [9].

In our previous study regarding the prevalence of allergic rhinitis in Turkey [10], many volunteers offered information 
about HTs that they had used to treat their allergic rhinitis symptoms. Here, we examine the use of HTs by patients with allergic rhinitis in Eskişehir, Turkey.

\section{Materials and Methods}

This study was performed at the Department of Otorhinolaryngology, Osmangazi University Medical Faculty, Eskişehir, Turkey. Patients who were diagnosed with perennial allergic rhinitis, between January 2012 and January 2013, were asked to answer a few questions about their use of herbal treatments. The subjects who accepted were included in this study. In all patients, allergy was diagnosed based on natural history, clinical examination, and skin prick tests. At the time of diagnosis, patients were questioned about their use of herbal supplements. Pediatric patients and subjects with seasonal allergic rhinitis were not included.

The questions were the following:

(1) have you used any kind of herbal treatment for your allergic condition?

(2) which herbal treatment did you use?

The available literature, up to January 2013, was searched using MedLine, with the key words allergic rhinitis [AND] complementary [OR] alternative medicine [OR] herbal. All retrieved trials and experimental studies were reviewed.

\section{Results}

By the end of the 1-year period, 230 patients were enrolled. Although we had more allergy patients, not all agreed to answer questions related to complimentary treatments.

The study group, with a mean age of 34 (range, 19-49) years, consisted of $162(70.4 \%)$ female and 68 (29.6\%) male subjects. Overall, $36.6 \%$ of the subjects had used a natural product or herbal therapy at least once. Women were more likely than men to have used herbal supplements (38.3\% versus $32.4 \%$ ). Ten different types of herbal supplement were primarily used, with Urtica diocia, Sambucus nigra, and Spirulina being the most common $(12.6 \%, 6.1 \%$, and $5.7 \%$, resp.). The herbal use results are summarized in Table 1.

\section{Discussion}

Turkey is a unique country; reflecting its geographic location between Europe and Asia, it combines a somewhat European culture with a strong background of Asian/oriental traditions. In a country where amulets and evil eye beads are still carried for healing, alternative medicine is of interest to many people. To date, only one reported study has addressed the use of alternative medicine by allergy patients in Turkey. That study evaluated patients with asthma, allergic rhinitis, and atopic dermatitis [11]. Among 70 patients with seasonal allergic rhinitis (SAR), the prevalence of HT use was $21.4 \%$. The use of natural products may be related to dissatisfaction with conventional medicine, fashionable trends, media promotions, politics, or the affects of various cultures that have settled in Anatolia through history. Friends and family members also commonly influence treatment choices for chronic conditions [11]. Education, geography, and public opinion are additional contributing factors [2]. Although studies have evaluated the use of herbal supplements, the actual prevalence of their use is likely to be higher than reported. A recent survey indicated that only $43 \%$ of subjects who had used CAM had informed a doctor about this [6].

The complimentary products found to be most commonly used in our study have been extensively described in the literature.

4.1. Stinging Nettle (Urtica diocia, UD). The leaves of the plant contain histamine, serotonin (5-hydroxytryptamine), and acetylcholine. Although it may seem inconsistent to use an extract that contains histamine to treat allergic rhinitis, subcutaneous and intravenous injections of histamine have been previously used to treat several allergic conditions such as cold urticaria with associated anaphylaxis, migraine, cluster headache associated with vasomotor rhinitis, penicillin reaction, and allergic arthritis [12]. It is also known that during allergen exposure, low plasma histamine levels, and not high plasma histamine levels, are associated with severe reactions [13]. A prospective, double-blind, comparative study of 69 allergic arthritis patients noted a significant benefit with UD versus placebo [14]. A more recent study also showed that UD inhibited proinflammatory pathways related to allergic rhinitis by antagonizing histamine 1 receptor, inhibiting prostaglandin (PG) formation and inhibiting degranulation [15].

4.2. Sambucus nigra (Elderberry). Although this plant is commonly used in alternative treatments, to our knowledge, there is no reported study focusing on the antiallergic properties of Sambucus nigra extracts. Previous data for this extract have documented its use as an antiviral agent for colds, influenza, and herpes virus infections, owing to its immunemodulating and antioxidant effects [16].

4.3. Spirulina. Spirulina is a blue-green alga that has been commercialized as a dietary supplement for modulating immune function, as well as ameliorating various diseases [17]. A previous study in allergic rhinitis patients demonstrated that Spirulina can modulate the Th cell profile by suppressing the differentiation of Th2 cells. It can also inhibit the production of IL-4 [18]. In an experimental study, it was effective for relieving inflammation of the nasal mucosa and decreasing serum histamine and immunoglobulin (Ig) E levels [19]. In our double-blind, placebo-controlled study to evaluate the effectiveness and tolerability of Spirulina in patients with allergic rhinitis, Spirulina consumption significantly improved the symptoms and physical findings, including nasal discharge, sneezing, nasal congestion, and itching, compared with placebo [17].

4.4. Butterbur (Petasites hybridus). Butterbur has been extensively studied, especially related to its beneficial effects in allergic rhinitis. In a comparative, randomized study in 125 patients with SAR, both butterbur (butterbur-carbon dioxide extract tablets, Ze 339; 1 tablet, 4 times/day; $n=61$ ) and 
TABLE 1: The prevalence of the herbal use among the study group.

\begin{tabular}{lccc}
\hline Herbal type & Male & Female & Total \\
\hline Urtica dioica & $7(3 \%)$ & $22(9.6 \%)$ & $29(12.6 \%)$ \\
Sambucus nigra (Elderberry) & $3(1.3 \%)$ & $11(4.8 \%)$ & $14(6.1 \%)$ \\
Spirulina & $5(2.1 \%)$ & $8(3.5 \%)$ & $13(5.7 \%)$ \\
Honey & $4(1.7 \%)$ & $6(2.6 \%)$ & $10(4.3 \%)$ \\
Butterbur & $1(0.4 \%)$ & $4(1.7 \%)$ & $5(2.1 \%)$ \\
Allium cepa (onion) & None & $4(1.7 \%)$ & $4(1.7 \%)$ \\
Prunus dulcis (almond) & $1(0.4 \%)$ & $3(1.3 \%)$ & $4(1.7 \%)$ \\
Petroselinum crispum (parsley) & $1(0.4 \%)$ & $2(0.9 \%)$ & $3(1.3 \%)$ \\
Lemon peel & None & $2(0.9 \%)$ & $2(0.9 \%)$ \\
Total & $22 / 68(32.4 \%)$ & $62 / 162(38.3 \%)$ & $84 / 230(36.6 \%)$ \\
\hline
\end{tabular}

cetirizine ( 1 tablet each evening; $n=64$ ) were effective in improving SF-36 and global improvement scores [20]. However, sedative effects were observed in the cetirizine group. Similar results were obtained in a more recent study comparing the efficacy of butterbur (Ze 339; $8 \mathrm{mg}$ total petasin; 1 tablet, 3 times/day), fexofenadine (180 $\mathrm{mg}$ once/day), and placebo in 330 patients [21]. Butterbur and fexofenadine were comparably effective, compared with placebo. Another study demonstrated that butterbur (Ze 339; 2 tablets, 3 times/day for 1 week) improved day and nighttime nasal symptoms, decreased nasal resistance as verified by rhinomanometry, and decreased anti-inflammatory mediators (histamine, LTB4, and cysteinyl-LT) in nasal fluids and serum [22]. Petasins (petasin, isopetasin, and neopetasin) are believed to be the pharmacologically active components of butterbur extracts [23]. A randomized, placebo-controlled study demonstrated that in sensitized patients, butterbur protected against adenosine monophosphate-induced nasal responsiveness during grass pollen season [24]. In contrast, a more recent study found no significant effect of butterbur (50 mg twice daily for 2 weeks) on peak nasal inspiratory flow, total nasal symptom score, eye symptom score, or quality of life in patients with intermittent allergic rhinitis, compared with placebo [25]. Dose-dependent effects were investigated in 186 patients with intermittent allergic rhinitis who were treated with butterbur Ze 339 (high dose: 1 tablet 3 times/day, $n=60$; low dose: 1 tablet twice daily, $n=65)$ or placebo $(n=$ 61) for 2 weeks [26]. Significant improvement of symptoms was observed with the use of butterbur, which showed a positive dose-dependent effect and side effects similar to those of the placebo. In an experimental study, an aqueous ethanol extract of the aerial parts of Japanese butterbur (JBE) directly suppressed smooth muscle contraction and inhibited cutaneous anaphylactic reactions; LT C4, D4, and E4 synthesis; TNF- $\alpha$ production; and mast cell degranulation [27]. An open postmarketing surveillance study on 580 patients (Ze 339; 2 tablets/day for 2 weeks) showed significant improvement in rhinorrhea, sneezing, nasal congestion, itchy eyes and nose, red eyes, and skin irritation associated with SAR in $90 \%$ of the patients [28]. An antiallergic comedication administered to $44 \%$ of the patients did not give a better result than that with Ze 339 monotherapy. Adverse events occurred at a rate of $3.8 \%$ in the study.
4.5. Lemon Peel. There is only one case report demonstrating the effectiveness of lemon peel in allergic rhinitis [29]. However, it has been noted that the peels of citrus fruits (grapefruit, lemon, lime, and orange) contain high levels of phenolics, flavonoids, ascorbic acid, and carotenoids, which have antioxidant properties [30].

4.6. Allium cepa (Onion). One experimental study has shown the antiallergic effects of Allium cepa. Although it has potential antihistamine, anti-inflammatory, and antioxidant activities [31], no study has addressed its use in allergic rhinitis.

4.7. Honey. In Turkey, honey is believed to be a beneficial supplement for various conditions. A previous study in 304 asthmatic families demonstrated that $26 \%$ of parents had previously used Turkish wild honey for their children's disease [32]. Only one study of 36 patients exists in the literature, and it did not find honey to be effective in allergic rhinitis, compared with placebo [33].

4.8. Prunus dulcis (Almond)/Petroselinum crispum (Parsley). Although some participants noted the use of these natural products, there are no reported studies addressing their use in allergic rhinitis.

A review of the literature on herbal treatments for the symptoms of allergic rhinitis revealed studies on the medicinal benefits of many more herbs and plants.

4.9. Moringa oleifera (MO) Lam. MO Lam. is a traditional herbal therapy in South Asia. The flowers, roots, seeds, and fruits of the plant are used for herbal therapy. The plant contains many important dietary elements such as proteins, minerals, and vitamins. More than 100 studies evaluating the effectiveness of this extract in various conditions have been reported, documenting its antioxidant, anticancer, antidiabetic, antihypertensive, antiepileptic, and cholesterollowering benefits [34]. Potential antiallergic effects of MO have been demonstrated in an experimental study [35]. MO extract inhibited inducible anaphylactic shock, passive cutaneous anaphylaxis activated by anti-IgE antibody, and histamine release from mast cells. 
4.10. Astragalus membranaceus (AM). Although more than 400 studies have been reported, only one focused on the effects of AM in SAR. This placebo-controlled, double-blind study revealed that the use of $A M$ had a beneficial effect in SAR [36]. In 48 subjects who had moderate to severe SAR, AM significantly decreased the intensity of rhinorrhea; however, the effects of AM on other symptoms did not differ from those of the placebo. Of note, AM was effective against SAR due to weed pollen allergy in this study.

4.11. Flos magnolia (FM). FM is reported to have antiinflammatory, antimicrobial and antiallergic activities [37]. Different FM species, which include Magnolia biondii, $M$. denudata, M. kobus, M. liliiflora, M. sargentiana, and M. sprengeri, exhibit different pharmacological properties. Ethanol extracts of FM produce a concentration-dependent inhibition of compound 48/80-induced histamine release and anti-inflammatory and antimicrobial activities [37].

4.12. Gyokuheifusan (GHS; Astragalus Root, Atractylodes Rhizome, and Saposhnikovia Root Combination). The potential usefulness of GHS in Japanese cedar pollen-induced allergic rhinitis has been demonstrated in guinea pigs [38]. In this murine model of antibody production, GHS significantly increased the concentration of ovalbumin-specific immunoglobulin in mice that were sensitized intraperitoneally to ovalbumin and upregulated the immune response in mice previously exposed to the antigen. In contrast, GHS significantly decreased ovalbumin-specific immunoglobulin in mice that were intranasally sensitized to the antigen. The authors suggested that GHS may consolidate the resistance of the nasal mucosa to protect against ovalbumin invasion, resulting in suppression of ovalbumin-specific antibodies in serum.

4.13. Biminne. This Chinese herbal formula consists of 11 different ingredients, including extracts of Scutellaria baicalensis (Baikal or Chinese skullcap), Ginkgo biloba (ginkgo), Epimedium sagittatum (yin yang huo or horny goat weed), and Schizandra chinensis (wu wei tzu or schizandra) and the pulp of Prunus Mume (Japanese apricot), Ledebouriella divaricata (Fang feng), and Astragalus membranaceus (astragalus). A randomized, double-blind, placebo-controlled study in 58 subjects demonstrated a beneficial effect on some allergic rhinitis symptoms and a decreased total serum IgE level [39]. Although the therapy period was 12 weeks, the beneficial effects persisted for 1 year. Another study reported that the frequency of sneezing and nasal rubbing was decreased with the use of biminne in mice in which an allergic rhinitis model was induced by intraperitoneal injection of ovalbumin; the serum total and ovalbumin-specific $\operatorname{IgE}$ levels were also decreased [35]. Biminne has also been shown to alter vascular permeability in the nasal mucosa of sensitized rats [40]. A more recent experimental study indicated that biminne therapy could downregulate Th2 cells [41]. Two relevant cytokines, interleukin-(IL-) 4 and IL-5, were also downregulated, whereas Thl cells and interferon- $\gamma$ were upregulated.
It was suggested that altering the Th2/Th1 ratio may explain the therapeutic effect of biminne in airway allergies.

4.14. RCM-101. In a previous randomized, placebo-controlled study, RCM-101 reduced SAR symptoms [42]. Possible tissue effects were evaluated in more recent studies. An experimental study demonstrated that RCM-101 inhibited the compound 48/80-induced release of histamine, PGE2, and LTB4; RCM-101 also inhibited the expression of cyclooxygenase(COX-) 2 protein, whereas COX-1 expression was not affected. [43]. More recently, possible multiple inhibitory actions of RCM-101 against inflammatory mediators have been described [43]. RCM-101 inhibited L-arginine-induced relaxation in endothelium-denuded rat aortic preparations and inhibited PGE2 and nitric oxide (NO) production in Raw 264.7 cells. Furthermore, RCM-101 and some of its ingredients (e.g., Radix glycyrrhizae, Radix bupleuri, Radix saposhnikoviae, and Atractylodis rhizoma macrocephalae) also inhibited NO production and inducible-NO synthase (NOS) protein expression in Raw 264.7 cells [44].

4.15. RCM-102. An experimental study showed the antiinflammatory effects of RCM-102 [45]. Intraperitoneal use of this herbal formula significantly decreased compound 48/80induced histamine release, NO and PGE2 production, and INOS and COX-2 expression.

4.16. Shi-Bi-Lin (SBL). This is a modified form of the classic Chinese formula Jia Wei Cang Er Zi San, [46] which has been used to treat allergic rhinitis, chronic rhinitis, and sinusitis for several centuries [47]. In a double-blind, placebocontrolled, randomized study with 126 subjects, SBL significantly decreased nasal blockage and enhanced some quality of life scores [48]. The effect of SBL lasted for 2 weeks after treatment, and no side effects were observed. In cell cultures, SBL significantly inhibited mast cell-derived IL-4 and TNF$\alpha$ secretion, whereas IL- 8 release and mRNA expression of these cytokines were not changed [46]. An experimental study in guinea pigs showed that SBL can suppress the production of IgG1 and decrease thromboxane B2 levels in nasal lavage fluid; the levels of histamine and peptide leukotrienes were not altered, but eosinophil infiltration and endothelial NOS immune reactivity were decreased in the nasal tissue [46].

4.17. Dishen Qufeng Decoction (DSQFD). A randomized clinical trial compared the effectiveness of DSQFD with that of cetirizine in 60 patients [49]. The total response rates to DSQFD and cetirizine were $83.3 \%$ and $86.7 \%$, respectively, and both effectively decreased the peripheral blood eosinophil count.

4.18. Hochuekkito (HET). A randomized, placebo-controlled study in 60 patients demonstrated that HET significantly improved nasal symptomatic scores. HET also suppressed total serum IgE as well as IL-4-stimulated production of PGE2 and leukotriene C4 and IL-4-stimulated expression of COX-2 mRNA in polymorphonuclear neutrophils [50]. 
4.19. Lycopus lucidus (LAE). LAE is an oriental herbal extract used in Republic of Korea. LAE has been shown to inhibit mast cell-derived, immediate-type allergic reactions [51]. In this study, LAE inhibited compound 48/80-induced systemic reactions in mice. It also had an inhibitory effect on proinflammatory cytokines, p38 mitogen-activated protein kinase, and nuclear factor-kappaB (NF- $\kappa \mathrm{B})$.

4.20. Aller-7/NR-A2. This polyherbal product is a mixture of seven herbal extracts (Phyllanthus emblica, Terminalia chebula, Terminalia bellerica, Albizia lebbeck, Piper nigrum, Zingiber officinale, and Piper longum). Its antioxidant [52], anti-inflammatory [53], antihistamine, antispasmodic, and mast cell stabilization activities [54] have been demonstrated in previous experimental studies. In a safety study performed according to the guidelines of the Organization for Economic Cooperation and Development, World Health Organization and US Environmental Protection Agency, no adverse effects and no fetal or maternal teratogenic effects were observed [55]. In another safety study, the "no observed adverse effect level" (NOAEL) of Aller-7 was greater than $1,000 \mathrm{mg} / \mathrm{kg}$ body weight [55]. A multicenter clinical trial demonstrated the efficacy of Aller-7 in 545 patients with allergic rhinitis, as sneezing, rhinorrhea, and nasal congestion were significantly improved [56]. Mucociliary clearance time, peak nasal inspiratory and expiratory flow rates, and absolute eosinophil count were also improved. No major, but some minor, side effects were observed with treatment.

4.21. Gamma-Tocopherol (GammaT). GammaT is the primary form of dietary vitamin E. In rats, acute gammaT therapy for 4 days blocked eosinophil infiltration into airspaces and tissues of the nose, sinus, and nasolacrimal duct [57]. Furthermore, gammaT decreased allergen-induced mucous cell metaplasia, increased goblet cell number, and amount of intraepithelial mucus storage in the nasal airway.

4.22. Gall of Rhus javanica (GRJ). A possible antianaphylactic effect was demonstrated for GRJ in an experimental study on mice, rats, and human mast cells [58]. GRJ inhibited compound 48/80-induced systemic reactions and decreased IgEmediated local allergic reactions. Additionally, GRJ inhibited histamine release from rat peritoneal mast cells activated by compound $48 / 80$ or IgE, in a dose-dependent manner. This effect was mediated by modulation of cAMP and $\left[\mathrm{Ca}^{2+}\right]_{i}$ in mast cells. GRJ also decreased TNF- $\alpha$ and IL- 6 secretion in human mast cells.

4.23. Houttuynia cordata Water Extract (HCWE). HCWE is a traditional herbal therapy with known antioxidant and anticancer activities. In mice, oral HCWE inhibited compound 48/80-induced systemic anaphylaxis. It also decreased compound 48/80-induced mast cell degranulation and colchicine-induced deformation of rat peritoneal mast cells (RPMCs). Additionally, HCWE inhibited histamine release and calcium uptake by RPMCs induced by compound 48/80 or anti-DNP IgE, in a dose-dependent manner. Thus, HCWE may be beneficial in the treatment of mast cell-mediated anaphylactic responses [59].

4.24. Moutan Cortex Radicis (MCR). MCR reduced the expression and secretion of eotaxin, a potent eosinophil-specific chemokine, inhibited eosinophil migration toward A549 medium, and suppressed the activation of NF- $\kappa \mathrm{B}$ [60].

4.25. Xinqin. In allergic rhinitis induced by 4 -toluene diisocyanate, xinqin tablets reduced symptoms of nasal hypersensitivity, decreased histamine release from the nasal mucosa, and inhibited NOS activity [61].

4.26. Kebimin Decoction (KD). In a study comparing KD and Xinfang rhinitis capsules, KD reduced the level of adhesion molecules and altered the Th1/Th2 balance, by decreasing Th1 cytokine levels and increasing Th2 cytokine levels, in allergic rhinitis patients [62].

4.27. Gamibojungikgitang (GBIT). GBIT, an oriental herbal extract, has been used to treat allergic rhinitis in Republic of Korea, China, and Japan. In an experimental study, GBIT inhibited compound 48/80-induced systemic anaphylactic shock in a dose-dependent manner [63]. Furthermore, GBIT pretreatment of rat peritoneal mast cells decreased compound 48/80-induced histamine release, in a dose-dependent manner. GBIT inhibited IL-6 secretion induced by phorbol 12-myristate 13-acetate (PMA) and a calcium ionophore (A23187) in human mast cells and inhibited passive cutaneous anaphylaxis activated by antidinitrophenyl IgE.

4.28. Isodon japonicus Hara (IJAE). The herbal extract IJAE has been used in Republic of Korea for its anti-inflammatory effects. In mice, IJAE inhibited compound 48/80-induced systemic reactions and decreased IgE-mediated local allergic reactions. Expression of TNF- $\alpha$ mRNA in HMC- 1 cells was also inhibited by IJAE. Additionally, IJAE inhibited histamine release from rat peritoneal mast cells activated by compound $48 / 80$ or IgE in a dose-dependent manner. GRJ also decreased TNF- $\alpha$ secretion in human mast cells [64]. In a previous study, it was shown that the extract inhibited IL-6 secretion induced by PMA and A23187 in human mast cells [65].

4.29. Bishudiwan. In an experimental allergic rhinitis model, bishudiwan was effective in relieving allergic rhinitis symptoms by decreasing serum IgE levels and decreasing nasal and serum histamine release [66].

4.30. Ryokan-kyomi-shinge-nin-to (RKS). The oriental herbal extract RKS is used in Japan. In an experimental study, RKS was shown to decrease sneezing and inhibit vascular permeability induced by histamine or serotonin, although it did not affect histamine release [67].

4.31. Sho-seiryu-to (SST). The major effective ingredient in SST is ephedrine [68]. SST has been shown to inhibit the secretion of water and electrolytes from the nasal glands, 
through an anticholinergic effect [69]. In a nasal allergy model in rats, SST had anti-type 1 allergy activity [70]. Among 914,612 Taiwanese subjects diagnosed with allergic rhinitis, $35.6 \%$ had taken Chinese herbal medicines [4] and SST was found to be one of the two most commonly used combination treatments. In an experimental study, the numbers of sneezes and scratches were significantly reduced by pretreatment with SST [71]. Eosinophil infiltration and volume changes in the nasal mucosa induced by LT D 4 were also inhibited. Another study demonstrated that SST could inhibit allergen-induced synthesis of TNF- $\alpha$, IgE, and IL-10, while levels of IL-5, IL-6, and IFN- $\gamma$ did not change [72]. SST may also suppress IL4 production in CD4+ T cells by influencing CD28-CD86 interactions [70] and may correct a Th2-dominant condition in allergic rhinitis [73].

4.32. Shin-yi-san + Xiao-qing-long-tang + Xiang-sha-liu-jun$z i$-tang Mixture. A study in allergic rhinitis patients showed that a 3-month treatment with this combination suppressed inflammation in the nasal mucosa [74]. The treatment normalized the stimulatory effects of allergic nasal discharge in patients with high-IgE allergic rhinitis. In another study, treatment with this combination decreased serum total and house dust mite-specific IgE levels [74]. Additionally, IL-10 levels were increased, while IL-5 and IFN- $\gamma$ production and COX-2 mRNA expression were decreased after treatment.

4.33. Grapeseed Extract. An 8-week, randomized, doubleblind, placebo-controlled study of treatment with grapeseed extract demonstrated no significant improvement in symptoms in SAR [75].

4.34. Tongkyutang (TKT). In a mouse model, TKT inhibited compound 48/80-induced histamine release from rat peritoneal mast cells, in a dose-dependent manner [76]. Oral administration of TKT also inhibited the passive cutaneous anaphylactic reaction induced by antidinitrophenyl $\operatorname{IgE}$ and IL-1 $\beta$ and TNF- $\alpha$ secretion induced by PMA and A23187.

4.35. Shosaiko-to (ST). Oral administration of ST significantly inhibited histamine release, in a dose-dependent manner [77]. However, the extract failed to inhibit compound 48/80-induced histamine release in mast cells. The authors suggested that ST inhibited IgE receptor-associated protein phosphorylation in the histamine release pathway.

4.36. Biminkang Mixture (Artemisia rupestris L). This extract is used primarily as a Kazak folk herb. When 162 patients with allergic rhinitis were treated with the extract and 52 subjects received a placebo, the total effectiveness and recurrence rates for the treatment versus control groups were 93.9 versus $69.2 \%$ and 46.8 versus $87.1 \%$, respectively [78].

4.37. Tian-huang-ling Granule (Larvae of a Silkworm with Batrytis, Milk Vetet, and Long-Spur Epimedium). In a study of 60 cases of allergic rhinitis, $96.6 \%$ of the subjects demonstrated symptomatic improvement [79]. No adverse effect was seen, and the results were better than those in subjects who received ketotifen. Additionally, total eosinophil and basophil blood counts were significantly decreased after the treatment.

4.38. Bu Qi Gu Biao. In total, 500 subjects with allergic rhinitis have been treated with this extract since 1980 [80]. A long-term curative effect was observed in $87 \%$ of the patients. Of these subjects, 200 underwent assessments that indicated the therapy could improve immune function and cyclic nucleotide metabolism. Blood flow in nasal mucosal tissue was improved as were cell shape and function.

\section{Conclusion}

There is growing worldwide interest in the use of herbal supplements for many indications. Some herbal treatments contain well-known active ingredients, which are known and accepted by modern medicine. Our examination of the prevalence of herbal treatments for allergic rhinitis in Turkey demonstrated that a high percentage of patients have used these products to relieve the symptoms of allergic rhinitis. These data may be unique to our country owing to its culture and tradition. For example, some products such as honey, onion, and parsley are believed to be healthy and curative and thus are widely used for many diseases. Increased use of these products in developed countries may be influenced more by hope than history.

Additional studies would help to clarify the active ingredients in herbal supplements used to treat allergic rhinitis and may lead to the development of new drugs from herbal extracts. Nevertheless, the placebo effect is a major issue that must always be considered with regard to the effectiveness of complimentary treatment modalities.

\section{References}

[1] G. Passalacqua, P. J. Bousquet, K. Carlsen et al., "ARIA update: I-Systematic review of complementary and alternative medicine for rhinitis and asthma," Journal of Allergy and Clinical Immunology, vol. 117, no. 5, pp. 1054-1062, 2006.

[2] M. R. Ritchie, "Use of herbal supplements and nutritional supplements in the UK: what do we know about their pattern of usage?" Proceedings of the Nutrition Society, vol. 66, no. 4, pp. 479-482, 2007

[3] G. B. Mahady, "Global harmonization of herbal health claims," Journal of Nutrition, vol. 131, supplement 3, pp. 1120S-1123S, 2001.

[4] J. H. Krouse and H. J. Krouse, "Patient use of traditional and complementary therapies in treating rhinosinusitis before consulting an otolaryngologist," Laryngoscope, vol. 109, no. 8, pp. 1223-1227, 1999.

[5] J. A. Félix Berumen, S. N. González Díaz, C. Canseco González, and A. Arias Cruz, "Use of alternative medicine in the treatment of allergic diseases," Revista Alergia México, vol. 51, no. 2, pp. 41$44,2004$.

[6] J. R. Newton, L. Santangeli, M. Shakeel, and B. Ram, "Use of complementary and alternative medicine by patients attending arhinology outpatient clinic," American Journal of Rhinology and Allergy, vol. 23, no. 1, pp. 59-63, 2009.

[7] A. Yakirevitch, L. Bedrin, L. Migirov, M. Wolf, and Y. P. Talmi, "Use of alternative medicine in Israeli chronic rhinosinusitis 
patients," Journal of Otolaryngology-Head and Neck Surgery, vol. 38, no. 4, pp. 517-520, 2009.

[8] M. K. Ang-Lee, J. Moss, and C. Yuan, "Herbal medicines and perioperative care," Journal of the American Medical Association, vol. 286, no. 2, pp. 208-216, 2001.

[9] M. Frieri, "Herbal therapies: what allergist-immunologists should know regarding patient use of complementary and alternative medicine," Allergy and Asthma Proceedings, vol. 22, no. 4, pp. 209-215, 2001.

[10] C. Cingi, B. Topuz, M. Songu et al., "Prevalence of allergic rhinitis among the adult population in Turkey," Acta OtoLaryngologica, vol. 130, no. 5, pp. 600-606, 2010.

[11] E. Kurt, S. Bavbek, G. Pasaoglu, O. Abadoglu, and Z. Misirligil, "Use of alternative medicines by allergic patients in Turkey," Allergologia et Immunopathologia, vol. 32, no. 5, pp. 289-294, 2004.

[12] P. Mittmann, "Randomized, double-blind study of freeze-dried urtica dioica in the treatment of allergic rhinitis," Planta Medica, vol. 56, no. 1, pp. 44-47, 1990.

[13] I. Zimmerman and W. T. Ulmer, "Effect of intravenous histamine, allergen (Ascaris suum extract) and compound 48/80 and inhaled allergen-aerosol on bronchoconstriction and histamine release," Respiration, vol. 42, no. 1, pp. 30-42, 1981.

[14] S. M. Thornhill and A. M. Kelly, "Natural treatment of perennial allergic rhinitis," Alternative Medicine Review, vol. 5, no. 5, pp. 448-454, 2000.

[15] B. Roschek Jr., R. C. Fink, M. McMichael, and R. S. Alberte, "Nettle extract (Urtica dioica) affects key receptors and enzymes associated with allergic rhinitis," Phytotherapy Research, vol. 23, no. 7, pp. 920-926, 2009.

[16] M. Roxas and J. Jurenka, "Colds and influenza: a review of diagnosis and conventional, botanical, and nutritional considerations," Alternative Medicine Review, vol. 12, no. 1, pp. 25-48, 2007.

[17] C. Cingi, M. Conk-Dalay, H. Cakli, and C. Bal, "The effects of spirulina on allergic rhinitis," European Archives of Oto-RhinoLaryngology, vol. 265, no. 10, pp. 1219-1223, 2008.

[18] T. K. Mao, J. Van de Water, and M. E. Gershwin, "Effects of a Spirulina-based dietary supplement on cytokine production from allergic rhinitis patients," Journal of Medicinal Food, vol. 8, no. 1, pp. 27-30, 2005.

[19] L. L. Chen, S. F. Zhang, D. N. Huang, J. Q. Tan, and S. H. He, "Experimental study of spirulina platensis in treating allergic rhinitis in rats," Journal of Central South University, vol. 30, no. 1, pp. 96-98, 2005.

[20] A. Schapowal, "Randomised controlled trial of butterbur and cetirizine for treating seasonal allergic rhinitis," British Medical Journal, vol. 324, no. 7330, pp. 144-146, 2002.

[21] A. Schapowal, "Treating intermittent allergic rhinitis: a prospective, randomized, placebo and antihistamine-controlled study of Butterbur extract Ze 339," Phytotherapy Research, vol. 19, no. 6, pp. 530-537, 2005.

[22] O. A. Thomet, A. Schapowal, I. V. Heinisch, U. N. Wiesmann, and H. Simon, "Anti-inflammatory activity of an extract of Petasites hybridus in allergic rhinitis," International Immunopharmacology, vol. 2, no. 7, pp. 997-1006, 2002.

[23] O. A. Thomet and H. U. Simon, "Petasins in the treatment of allergic diseases: results of preclinical and clinical studies," International Archives of Allergy and Immunology, vol. 129, no. 2, pp. 108-112, 2002.
[24] D. K. Lee, I. J. Carstairs, K. Haggart, C. M. Jackson, G. P. Currie, and B. J. Lipworth, "Butterbur, a herbal remedy, attenuates adenosine monophosphate induced nasal responsiveness in seasonal allergic rhinitis," Clinical and Experimental Allergy, vol. 33, no. 7, pp. 882-886, 2003.

[25] R. D. Gray, K. Haggart, D. K. C. Lee, S. Cull, and B. J. Lipworth, "Effects of butterbur treatment in intermittent allergic rhinitis: a placebo-controlled evaluation," Annals of Allergy, Asthma and Immunology, vol. 93, no. 1, pp. 56-60, 2004.

[26] A. Schapowal, "Butterbur Ze339 for the treatment of intermittent allergic rhinitis: dose-dependent efficacy in a prospective, randomized, double-blind, placebo-controlled study," Archives of Otolaryngology-Head and Neck Surgery, vol. 130, no. 12, pp. 1381-1386, 2004.

[27] H. Shimoda, J. Tanaka, E. Yamada, T. Morikawa, N. Kasajima, and M. Yoshikawa, "Anti type I allergic property of Japanese butterbur extract and its mast cell degranulation inhibitory ingredients," Journal of Agricultural and Food Chemistry, vol. 54, no. 8, pp. 2915-2920, 2006.

[28] R. Käufeler, W. Polasek, A. Brattström, and U. Koetter, "Efficacy and safety of butterbur herbal extract Ze 339 in seasonal allergic rhinitis: postmarketing surveillance study," Advances in Therapy, vol. 23, no. 2, pp. 373-384, 2006.

[29] K. G. Vazouras, J. Partheniou, and I. D. Dimoliatis, "Alleviation and prevention of severe allergic rhinitis and conjunctivitis following long-term lemon juice use: a case report," Cases Journal, vol. 2, no. 8, Article ID 8971, 2009.

[30] R. Guimarães, L. Barros, J. C. M. Barreira, M. J. Sousa, A. M. Carvalho, and I. C. F. R. Ferreira, "Targeting excessive free radicals with peels and juices of citrus fruits: grapefruit, lemon, lime and orange," Food and Chemical Toxicology, vol. 48, no. 1, pp. 99-106, 2010.

[31] P. Kaiser, M. S. Youssouf, S. A. Tasduq et al., "Anti-allergic effects of herbal product from Allium cepa (Bulb)," Journal of Medicinal Food, vol. 12, no. 2, pp. 374-382, 2009.

[32] F. Orhan, B. E. Sekerel, C. N. Kocabas, C. Sackesen, G. Adalioglu, and A. Tuncer, "Complementary and alternative medicine in children with asthma," Annals of Allergy, Asthma and Immunology, vol. 90, no. 6, pp. 611-615, 2003.

[33] T. V. Rajan, H. Tennen, R. L. Lindquist, L. Cohen, and J. Clive, "Effect of ingestion of honey on symptoms of rhinoconjunctivitis," Annals of Allergy, Asthma and Immunology, vol. 88, no. 2, pp. 198-203, 2002.

[34] F. Anwar, S. Latif, M. Ashraf, and A. H. Gilani, "Moringa oleifera: a food plant with multiple medicinal uses," Phytotherapy Research, vol. 21, no. 1, pp. 17-25, 2007.

[35] R. H. Liu, X. M. Zhang, and S. Q. Zhang, "Study on mechanism of biminne in treating allergic rhinitis," Zhongguo Zhong Xi Yi Jie He Za Zhi, vol. 27, no. 7, pp. 623-625, 2007.

[36] Z. Matkovic, V. Zivkovic, M. Korica, D. Plavec, S. Pecanic, and N. Tudoric, "Efficacy and safety of Astragalus membranaceus in the treatment of patients with seasonal allergic rhinitis," Phytotherapy Research, vol. 24, no. 2, pp. 175-181, 2010.

[37] Y. Shen, E. C. Pang, C. C. Xue, Z. Z. Zhao, J. G. Lin, and C. $\mathrm{G}$. Li, "Inhibitions of mast cell-derived histamine release by different Flos Magnoliae species in rat peritoneal mast cells," Phytomedicine, vol. 15, no. 10, pp. 808-814, 2008.

[38] T. Makino, S. Sasaki, Y. Ito, and Y. Kano, "Pharmacological properties of traditional medicine (XXX): effects of Gyokuheifusan ([Symbol: see text]) on murine antigen-specific antibody production," Biological and Pharmaceutical Bulletin, vol. 28, no. 1, pp. 110-113, 2005. 
[39] G. Hu, R. S. Walls, D. Bass et al., "The Chinese herbal formulation Biminne in management of perennial allergic rhinitis: a randomized, double-blind, placebo-controlled, 12-week clinical trial," Annals of Allergy, Asthma and Immunology, vol. 88, no. 5, pp. 478-487, 2002.

[40] Y. F. Gu, X. M. Zhang, and G. R. Hu, "Effect of biminne on vascular permeability of nasal mucosa in allergic rhinitis rats," Zhongguo Zhong Xi Yi Jie He Za Zhi, vol. 26, no. 10, pp. 918-921, 2006.

[41] S. Q. Zhang, Z. Y. Shen, G. R. Hu, R. Liu, and X. Zhang, "Effects of Chinese herbal formula Biminne in regulating endocrineimmune function in mice with airway allergy," Journal of Chinese Integrative Medicine, vol. 7, no. 4, pp. 349-353, 2009.

[42] C. C. Xue, F. C. Thien, J. J. Zhang, C. Da Costa, and C. G. $\mathrm{Li}$, "Treatment for seasonal allergic rhinitis by Chinese herbal medicine: a randomized placebo controlled trial," Alternative Therapies in Health and Medicine, vol. 9, no. 5, pp. 80-87, 2003.

[43] G. B. Lenon, C. C. L. Xue, D. F. Story, F. C. K. Thien, S. McPhee, and C. G. Li, "Inhibition of release of inflammatory mediators in primary and cultured cells by a Chinese herbal medicine formula for allergic rhinitis," Chinese Medicine, vol. 2, p. 2, 2007.

[44] G. B. Lenon, C. G. Li, C. C. Xue, F. C. K. Thien, and D. F. Story, "Inhibition of inducible nitric oxide production and iNOS protein expression in lipopolysaccharide-stimulated rat aorta and Raw 264.7 macrophages by ethanol extract of a Chinese herbal medicine formula (RCM-101) for allergic rhinitis," Journal of Ethnopharmacology, vol. 116, no. 3, pp. 547-553, 2008.

[45] G. B. Lenon, C. C. Xue, D. F. Story, F. C. K. Thien, and G. L. Chun, "Inhibition of release of inflammatory mediators in rat peritoneal mast cells and murine macrophages by a Chinese herbal medicine formula (RCM-102)," Phytotherapy Research, vol. 23, no. 9, pp. 1270-1275, 2009.

[46] Y. Zhao, C. A. van Hasselt, J. K. Woo et al., "Effect of a Chinese herbal formula, Shi-Bi-Lin, on an experimental model of allergic rhinitis," Annals of Allergy, Asthma and Immunology, vol. 96, no. 6, pp. 844-850, 2006.

[47] Y. Zhao, C. A. van Hasselt, J. K. Woo et al., "Effects of the Chinese herbal formula Shi-Bi-Lin on cytokine release from the human mast cell line," Annals of Allergy, Asthma and Immunology, vol. 95, no. 1, pp. 79-85, 2005.

[48] Y. Zhao, K. S. Woo, K. H. Ma et al., "Treatment of perennial allergic rhinitis using Shi-Bi-Lin, a Chinese herbal formula," Journal of Ethnopharmacology, vol. 122, no. 1, pp. 100-105, 2009.

[49] W. R. Zhu, S. J. Zhang, D. H. Deng, and X. Shen, "Dishen Qufeng Decoction for treating allergic rhinitis: a randomized controlled trial," Journal of Chinese Integrative Medicine, vol. 6, no. 7, pp. 700-703, 2008.

[50] S. H. Yang and C. L. Yu, "Antiinflammatory effects of Bu-zhongyi-qi-tang in patients with perennial allergic rhinitis," Journal of Ethnopharmacology, vol. 115, no. 1, pp. 104-109, 2008.

[51] T. Y. Shin, S. H. Kim, K. Suk et al., "Anti-allergic effects of Lycopus lucidus on mast cell-mediated allergy model," Toxicology and Applied Pharmacology, vol. 209, no. 3, pp. 255-262, 2005.

[52] P. D’Souza, A. Amit, V. S. Saxena, D. Bagchi, M. Bagchi, and S. J. Stohs, "Antioxidant properties of aller-7, a novel polyherbal formulation for allergic rhinitis," Drugs under Experimental and Clinical Research, vol. 30, no. 3, pp. 99-109, 2004.

[53] N. Pratibha, V. S. Saxena, A. Amit, P. D’Souza, M. Bagchi, and D. Bagchi, "Anti-inflammatory activities of aller-7, a novel polyherbal formulation for allergic rhinitis," International Journal of Tissue Reactions, vol. 26, no. 1-2, pp. 43-51, 2004.
[54] A. Amit, A. J. Joshua, M. Bagchi, and D. Bagchi, "Safety of a novel botanical extract formula for ameliorating allergic rhinitis. Part II," Toxicology Mechanisms and Methods, vol. 15, no. 3, pp. 193-204, 2005.

[55] A. Amit, V. S. Saxena, N. Pratibha, M. Bagchi, D. Bagchi, and S. J. Stohs, "Safety of a novel botanical extract formula for ameliorating allergic rhinitis," Toxicology Mechanisms and Methods, vol. 13, no. 4, pp. 253-261, 2003.

[56] V. S. Saxena, K. Venkateshwarlu, P. Nadig et al., "Multicenter clinical trials on a novel polyherbal formulation in allergic rhinitis," International Journal of Clinical Pharmacology Research, vol. 24, no. 2-3, pp. 79-94, 2004.

[57] J. G. Wagner, Q. Jiang, J. R. Harkema et al., " $\gamma$-Tocopherol prevents airway eosinophilia and mucous cell hyperplasia in experimentally induced allergic rhinitis and asthma," Clinical and Experimental Allergy, vol. 38, no. 3, pp. 501-511, 2008.

[58] S. Kim, H. Park, S. Lee et al., "The anti-anaphylactic effect of the gall of Rhus javanica is mediated through inhibition of histamine release and inflammatory cytokine secretion," International Immunopharmacology, vol. 5, no. 13-14, pp. 18201829, 2005.

[59] J. S. Lee, I. S. Kim, J. H. Kim, J. S. Kim, D. H. Kim, and C. Y. Yun, "Suppressive effects of Houttuynia cordata Thunb (Saururaceae) extract on Th2 immune response," Journal of Ethnopharmacology, vol. 117, no. 1, pp. 34-40, 2008.

[60] J. Kim, H. Lee, Y. Lee et al., "Inhibition effects of Moutan Cortex Radicis on secretionof eotaxin in A549 human epithelial cells and eosinophil migration," Journal of Ethnopharmacology, vol. 114, no. 2, pp. 186-193, 2007.

[61] R. Zhang, Y. Yu, J. R. Du et al., "Influence of Xinqin tablets on guinea-pig nasal hypersensitivity," Zhongguo Zhongyao Zazhi, vol. 30, no. 10, pp. 785-788, 2005.

[62] L. Cheng, S. Zhang, and J. Xu, "Effect of kebimin decoction on serum levels of adhesion molecule and Th1/Th2 cytokines in patients with allergic rhinitis," Zhongguo Zhong Xi Yi Jie He Za Zhi, vol. 25, no. 6, pp. 505-507, 2005.

[63] P. D. Moon, J. J. Na, H. J. Jeong et al., "Inhibitory effect of gamibojungikgitang extract on mast cell-mediated allergic reaction in murine model," Journal of Pharmacy and Pharmaceutical Sciences, vol. 8, no. 1, pp. 94-101, 2005.

[64] T. Y. Shin, S. H. Kim, C. H. Choi, H. Shin, and H. Kim, "Isodon japonicus decreases immediate-type allergic reaction and tumor necrosis factor- $\alpha$ production," International Archives of Allergy and Immunology, vol. 135, no. 1, pp. 17-23, 2004.

[65] S. Y. Kim, Y. G. Choi, S. H. Kim et al., "Isodon japonicus inhibits mast cell-mediated immediate-type allergic reactions," Immunopharmacology and Immunotoxicology, vol. 26, no. 2, pp. 273-284, 2004.

[66] M. Zhang, Y. Ren, C. S. Song et al., "Effect and mechanism of bishudiwan (BSDW) against allergy," Zhongguo Zhongyao Zazhi, vol. 28, no. 6, pp. 543-544, 2003.

[67] M. Sakaguchi, Y. Ikeda, T. Kido et al., "Pharmacological characteristics of Ryokan-kyomi-shinge-nin-to, an antiallergic Kampo medicine," Biological and Pharmaceutical Bulletin, vol. 25, no. 12, pp. 1562-1565, 2002.

[68] A. Yafune and J. C. Cyong, "Population pharmacokinetic analysis of ephedrine in Kampo prescriptions: a study in healthy volunteers and clinical use of the pharmacokinetic results," International Journal of Clinical Pharmacology Research, vol. 21, no. 2, pp. 95-102, 2001.

[69] K. Ikeda, D. Z. Wu, M. Ishigaki, H. Sunose, and T. Takasaka, "Inhibitory effects of sho-seiryu-to on acetylcholine-induced 
responses in nasal gland acinar cells," American Journal of Chinese Medicine, vol. 22, no. 2, pp. 191-196, 1994.

[70] Y. Ikeda, A. Kaneko, M. Yamamoto, A. Ishige, and H. Sasaki, "Possible involvement of suppression of Th2 differentiation in the anti-allergic effect of Sho-seiryu-to in mice," Japanese Journal of Pharmacology, vol. 90, no. 4, pp. 328-336, 2002.

[71] M. Sakaguchi, A. Mase, Y. Ikeda et al., "Effects of Sho-seiryu-to on experimental allergic rhinitis in guinea pigs," Methods and Findings in Experimental and Clinical Pharmacology, vol. 21, no. 4, pp. 303-308, 1999.

[72] A. Tanaka, Y. Ohashi, Y. Kakinoki et al., "The herbal medicine shoseiryu-to inhibits allergen-induced synthesis of tumour necrosis factor alpha by peripheral blood mononuclear cells in patients with perennial allergic rhinitis," Acta Oto-Laryngologica, no. 538, pp. 118-125, 1998.

[73] E. Ko, S. Rho, E. J. Lee et al., "Traditional Korean medicine (SCRT) modulate Th1/Th2 specific cytokine production in mice CD4+ T cell," Journal of Ethnopharmacology, vol. 92, no. 1, pp. 121-128, 2004.

[74] S. H. Yang, C. Y. Hong, and C. L. Yu, "The stimulatory effects of nasal discharge from patients with perennial allergic rhinitis on normal human neutrophils are normalized after treatment with a new mixed formula of Chinese herbs," International Immunopharmacology, vol. 2, no. 12, pp. 1627-1639, 2002.

[75] D. I. Bernstein, C. K. Bernstein, C. Deng et al., "Evaluation of the clinical efficacy and safety of grapeseed extract in the treatment of fall seasonal allergic rhinitis: a pilot study," Annals of Allergy, Asthma and Immunology, vol. 88, no. 3, pp. 272-278, 2002.

[76] H. J. Na, H. J. Jeong, H. Bae et al., “Tongkyutang inhibits mast cell-dependent allergic reactions and inflammatory cytokines secretion," Clinica Chimica Acta, vol. 319, no. 1, pp. 35-41, 2002.

[77] T. Matsumoto and T. Shibata, "The ex vivo effect of the herbal medicine Sho-saiko-to on histamine release from rat mast cells," European Archives of Oto-Rhino-Laryngology, vol. 255, no. 7, pp. 359-364, 1998.

[78] L. Bao, Q. W. Sun, and L. Hu, "Clinical and experimental study for allergic rhinitis with treatment of biminkang mixture," Zhongguo Zhong Xi Yi Jie He Za Zhi, vol. 17, no. 2, pp. 70-72, 1997.

[79] Y. J. Yu, "Effect of tian-huang-ling granule in the treatment of allergic rhinitis," Zhong Xi Yi Jie He Za Zhi, vol. 9, no. 12, pp. 720-708, 1989.

[80] W. S. Lin, "Clinical study of allergic rhinitis treated by "bu qi gu biao" therapy," Zhongguo Zhong Xi Yi Jie He Za Zhi, vol. 9, no. 5, pp. 263-259, 1989. 


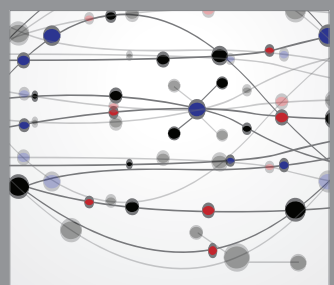

The Scientific World Journal
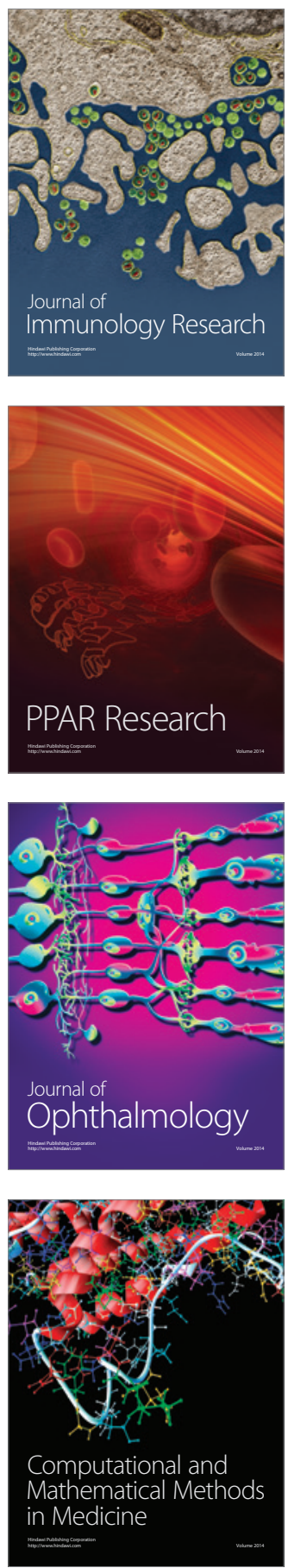

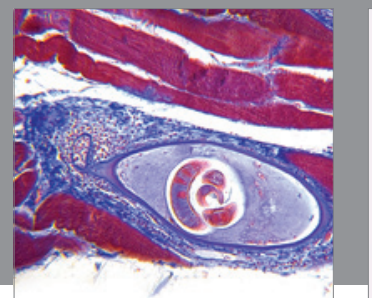

Gastroenterology

Research and Practice
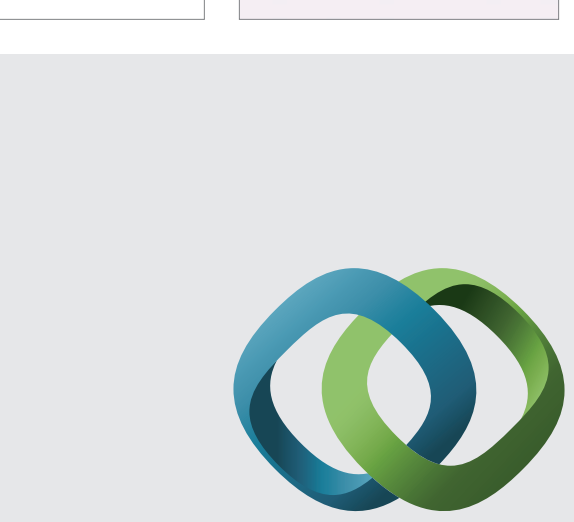

\section{Hindawi}

Submit your manuscripts at

http://www.hindawi.com
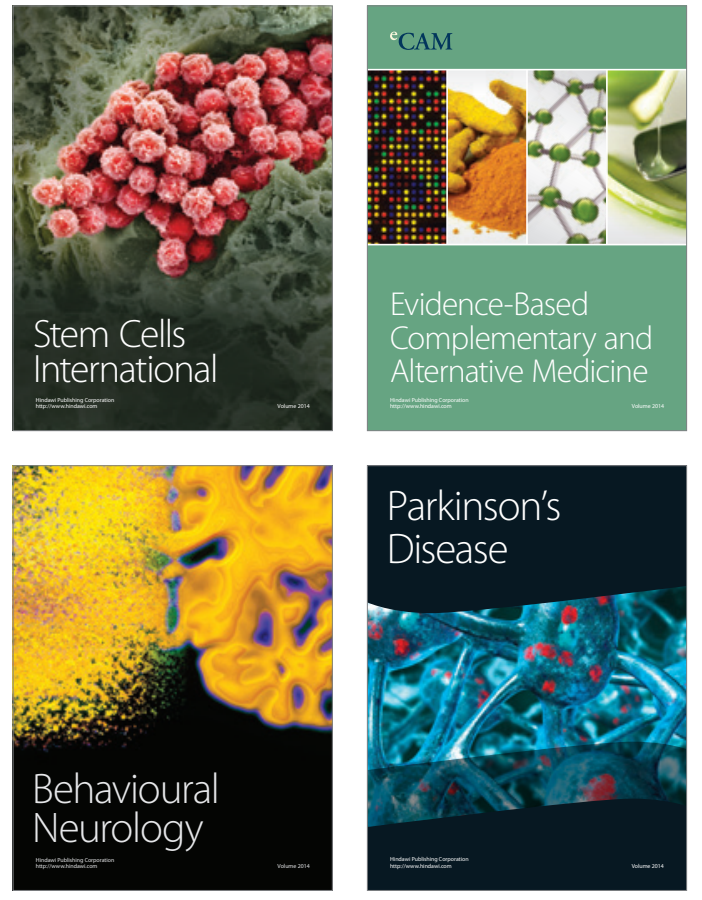
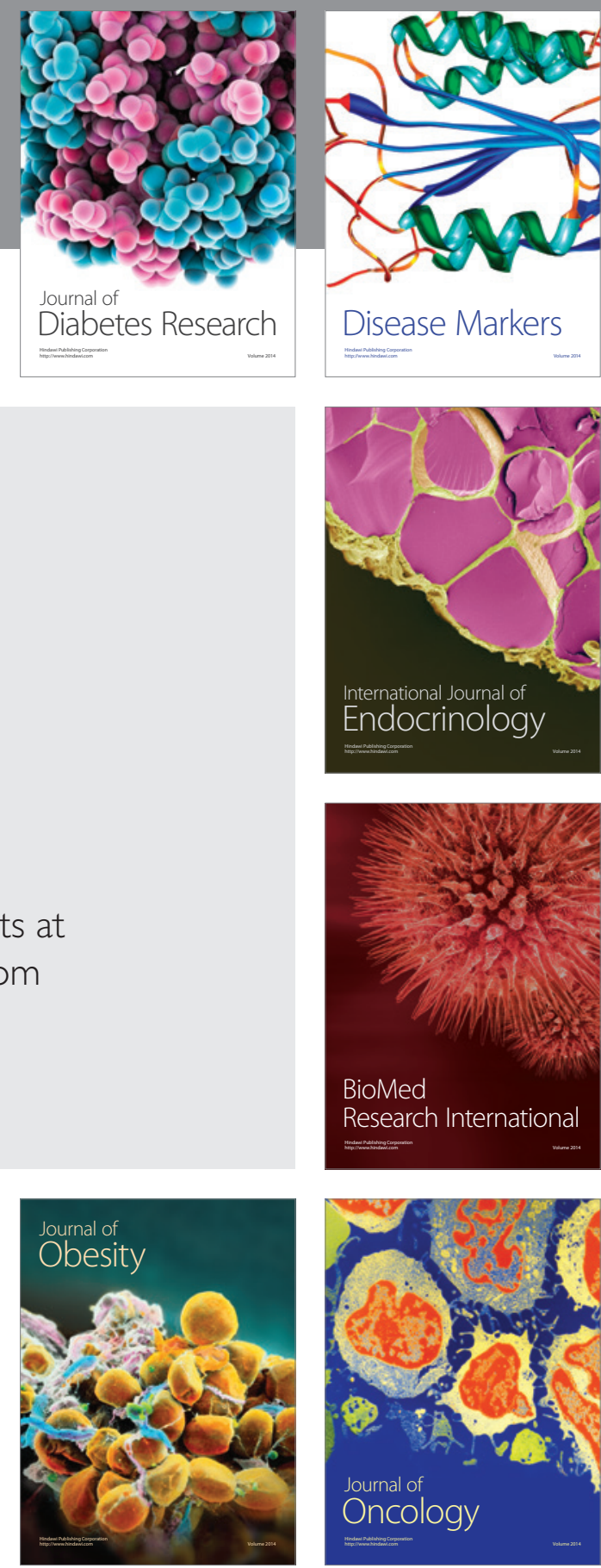

Disease Markers
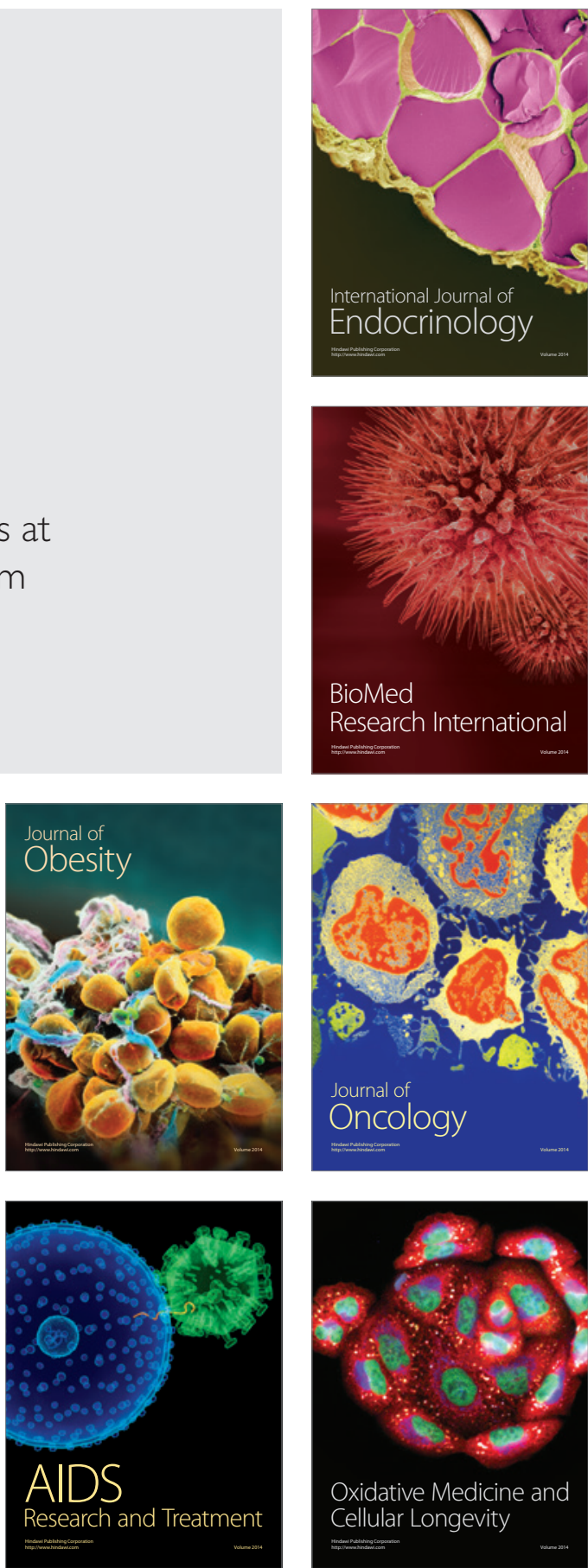